Check for updates

Cite this: RSC Adv., 2018, 8, 41594

\title{
Adsorption-desorption of $\mathrm{CO}_{2}$ on zeolite-Y- templated carbon at various temperatures $\uparrow$
}

\author{
Triyanda Gunawan, (D) Rika Wijiyanti and Nurul Widiastuti (D) *
}

Received 7th November 2018

Accepted 28th November 2018

DOI: $10.1039 / \mathrm{c} 8 \mathrm{ra09200a}$

rsc.li/rsc-advances

\begin{abstract}
This study aims to investigate the adsorption-desorption of $\mathrm{CO}_{2}$ on a micro-mesoporous zeolite-Ytemplated carbon (ZTC) at various temperatures. ZTC was synthesized via sucrose impregnation, carbonization, and template removal. The adsorption-desorption of $\mathrm{CO}_{2}$ on ZTC was performed using the gravimetric method. Results showed that the $\mathrm{CO}_{2}$ adsorption capacity was $9.51 \mathrm{wt} \%, 5.60$ wt $\%$, and $3.47 \mathrm{wt} \%$, and desorbed up to $59.83 \%, 69.70 \%, 77.5 \%$ for temperatures of $30{ }^{\circ} \mathrm{C}, 40{ }^{\circ} \mathrm{C}$, and $50{ }^{\circ} \mathrm{C}$, respectively. The adsorption process of $\mathrm{CO}_{2}$ at temperatures of $30{ }^{\circ} \mathrm{C}$ and $40{ }^{\circ} \mathrm{C}$ follow the pseudosecond order, while at $50{ }^{\circ} \mathrm{C}$ follows intra-particle diffusion. The thermodynamic analyses indicate that the adsorption was due to physisorption.
\end{abstract}

\section{Introduction}

Global warming caused by greenhouse gas emissions has attracted some researchers to solve this issue. $\mathrm{CO}_{2}$ is the main contributor to global warming with a $60 \%$ contribution among all greenhouse gasses. ${ }^{\mathbf{1 - 3}}$ This could be because this gas is emitted in large amounts by industrial processes and from the combustion of fuels. ${ }^{4}$ The $\mathrm{CO}_{2}$ concentration in our atmosphere nowadays is nearly $400 \mathrm{ppm}$, which is way higher than that of the pre-industrial era, which was 300 ppm. ${ }^{5}$ Moreover, the presence of $\mathrm{CO}_{2}$ in a natural gas source reduced the heat value. Thus, there is a strong desire to reduce the $\mathrm{CO}_{2}$ concentration. Carbon capture and storage (CCS) is one approach to reduce this greenhouse gas. ${ }^{1-3}$

In the past, $\mathrm{CO}_{2}$ was captured by utilizing various ethanolamine solutions via a chemical absorption mechanism. However, this application required high operating costs because the absorbent was lost very easily and because the application required a lot of energy. ${ }^{6}$ Adsorption by a porous solid is a promising alternative to this issue in terms of the energy saving and ease of operation. There are three main requirements to develop a $\mathrm{CO}_{2}$ adsorbent: high adsorption capacity of $\mathrm{CO}_{2}$, adequate adsorption/desorption kinetics for carbon dioxide at operating conditions, and long-lasting after a repeated adsorption/desorption cycle., ${ }^{4,7-9}$

Carbons, zeolites, ordered mesoporous materials, and silica are physisorption-based materials that are mostly used for $\mathrm{CO}_{2}$ capture today. ${ }^{\mathbf{1 0}}$ Among those materials, zeolites and carbons are the most interesting. Zeolite is an alumina-

Department of Chemistry, Faculty of Science, Institut Teknologi Sepuluh Nopember, 60111 Surabaya, Indonesia. E-mail: nurul_widiastuti@chem.its.ac.id

$\dagger$ Electronic supplementary information (ESI) available. See DOI: 10.1039/c8ra09200a silicate material, which has a high microporosity, and its pore surface is easily adjusted depending on the desired application. The pores can be micropores $(<2 \mathrm{~nm})$ or mesopores $(2-50 \mathrm{~nm})$, and are well distributed. However, a zeolite has the disadvantage that its surface area is lower than that of carbon materials and is easily poisoned by $\mathrm{CO}_{2}$ in the presence of moisture. ${ }^{7,11}$ On the other hand, carbon materials have high specific surface areas up to $300-1000 \mathrm{~m}^{2} \mathrm{~g}^{-1}$ or even more, while their porosities are lower than that of a zeolite. Zeolite has a cage-like pore structure with a molecular size of $0.5-1.2 \mathrm{~nm}$. A high porosity zeolite can capture 0.45-6.52 $\mathrm{mmol} \mathrm{g}^{-1} \mathrm{CO}_{2}$ at room temperature, while high surface carbon can capture $21.29 \mathrm{mmol} \mathrm{g}^{-1} \mathrm{CO}_{2}$ at room temperature. $^{\mathbf{1 2}}$ Based on these research, the idea of combining both materials arose to produce a material that has the advantages of both materials. It overcomes the shortcomings of the two materials, so that high porosity and high surface area can be obtained in one material to maximize the adsorption of $\mathrm{CO}_{2}$. This material can be synthesized using a carbon template zeolite method.

The pore structure formed in the as-synthesized carbon template zeolite depends on the synthetic conditions. ${ }^{13,14}$ One of the simplest methods for synthesizing this material is using an impregnation method. ${ }^{15,16}$ Basically, this method is conducted by adding a carbon precursor into the pore of a hard template material, followed by carbonization at 500-1000 ${ }^{\circ} \mathrm{C}$ under $\mathrm{N}_{2}$ flow and finally undergo an acid treatment to remove the zeolite template. In a previous study, Zhou et al. and Youn et al. utilized zeolite-Y as a hard template to produce a high microporosity ZTC. ${ }^{17,18}$ The materials exhibited a large amount of adsorbed $\mathrm{CO}_{2}$ capacity, up to $9.3 \mathrm{wt} \%$ at room temperature and a high pressure of 40-100 $\mathrm{kPa}$. However, the literature discussing detailed $\mathrm{CO}_{2}$ adsorption-desorption at room pressure and temperature is limited. 
In the present study, the adsorption-desorption of $\mathrm{CO}_{2}$ on ZTC was studied. ZTC was prepared by an impregnation carbon source inside a zeolite-Y pore. Sucrose was used as a carbon precursor due to its high availability, high carbon residue and low cost, compared to other carbon sources. ${ }^{\mathbf{1 9 , 2 0}}$ The $\mathrm{CO}_{2}$ adsorption-desorption was conducted at $30^{\circ} \mathrm{C}, 40{ }^{\circ} \mathrm{C}$ and $50{ }^{\circ} \mathrm{C}$ at a pressure of $1 \mathrm{bar}$. A thermodynamic and kinetic study was undertaken to observe the gas transport mechanisms.

\section{Experimental}

\section{Materials}

Sulfuric acid $\left(\mathrm{H}_{2} \mathrm{SO}_{4}, 98 \%\right)$ was purchased from Merck. Sodium aluminate $\left(\mathrm{NaAlO}_{2}\right.$, Sigma Aldrich) was used as an aluminate and sodium source for zeolite formation. Sodium silicate $\left(\mathrm{Na}_{2} \mathrm{SiO}_{3}\right.$, Sigma Aldrich) was used as a silicate and sodium source and sodium hydroxide (99\% $\mathrm{NaOH}$, pellet) was purchased from Sigma Aldrich for an additional sodium source and as a counter ion of zeolite. Sucrose (98\%, Fluka) was used as a carbon source for ZTC.

\section{Procedure}

Synthesis of zeolite-Y. The overall synthesis route of ZTC can be seen in Fig. 1. Zeolite-Y was synthesized via a hydrothermal reaction of zeolite seed crystals. The molar composition of the gel was $1.0 \mathrm{NaAlO}_{2}: 18 \mathrm{Na}_{2} \mathrm{SiO}_{3}: 1.75 \mathrm{NaOH}: 23.33 \mathrm{H}_{2} \mathrm{O} .^{21}$ The gel was prepared by dissolving $\mathrm{NaOH}$ and $\mathrm{NaAlO}_{2}$ into DI water. The solution was stirred at room temperature until a homogenous aluminate solution was obtained. Then, $\mathrm{Na}_{2} \mathrm{SiO}_{3}$ was added dropwise into the aluminate solution and stirred for 20 minutes. The solution was then moved into a stainless steel autoclave and aged for 1 day. The hydrothermal reaction was conducted in an oven at $100{ }^{\circ} \mathrm{C}$ for $7 \mathrm{~h}$. The zeolite was then filtered and washed until the $\mathrm{pH}$ of the filters reached $<9$, followed by drying at $110{ }^{\circ} \mathrm{C}$ for $24 \mathrm{~h}$. The white powder zeolite mass was then measured and stored in a desiccator for the next purpose.

Synthesis of zeolite-Y-templated carbon. The as-synthesized zeolite-Y was used as a hard template for preparing the ZTC. First, the zeolite-carbon composite was synthesized via an impregnation method..$^{19}$ Zeolite-Y was degassed at $200{ }^{\circ} \mathrm{C}$ for $4 \mathrm{~h}$ inside a homemade tubular furnace with a heating rate of $1{ }^{\circ} \mathrm{C} \min ^{-1}$ to remove any adsorbed gasses prior to the impregnation process. The mass ratio of zeolite-Y and sucrose was $1: 1.25$. The impregnation process was carried out by dissolving sucrose into $50 \mathrm{~mL}$ of $0.35 \mathrm{M} \mathrm{H}_{2} \mathrm{SO}_{4}$. The zeolite $\mathrm{Y}$ has a high resistance toward sulfuric acid, up to $5 \mathrm{M}$ of sulfuric acid. ${ }^{22}$ Then, degassed zeolite-Y was added and the solution was

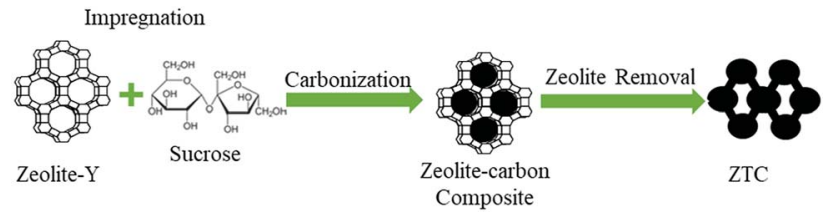

Fig. 1 Synthesis route of ZTC. stirred at $250 \mathrm{rpm}$ for $72 \mathrm{~h}$ at room temperature. The solution was then filtered and its residue (the impregnated zeolite) was moved into a tubular holder prior to the carbonization process. The pyrolysis process was conducted inside a homemade tubular furnace at $800{ }^{\circ} \mathrm{C}$ for $4 \mathrm{~h}$ with a heating rate of $2{ }^{\circ} \mathrm{C} \mathrm{min}^{-1}$, under a $\mathrm{N}_{2}$ flow of $30 \mathrm{~cm}^{3} \mathrm{~min}^{-1}$. The zeolite-carbon composite was then ground to obtain a fine powder and immersed in $5 \% \mathrm{HF}$ for $1 \mathrm{~h}$ to break the Si bonding in the zeolite. The Al phase was removed by refluxing the sorbent at $60{ }^{\circ} \mathrm{C}$ in $37 \%$ hydrochloric acid $(\mathrm{HCl})$ and was finally immersed in $48 \% \mathrm{HF}$ for $1 \mathrm{~h}$ to completely remove the zeolite template. After each acid treatment, the sample was dried at $110^{\circ} \mathrm{C}$. The ZTC obtained was then stored inside a desiccator for future treatment.

Sample characterization. $\mathrm{Cu} \mathrm{K} \alpha$ radiation X-ray diffractogram (XRD) observations were performed on a Brucker D8 Advance diffractometer. The morphology of each sample was observed using a scanning electron microscope (Hitachi, TM 3000 ) with a potential of $15 \mathrm{kV}$ and samples were coated with platinum. A high resolution transmission electron microscope (H9500) was employed to observe the carbon microstructure.

The pore properties were measured using a surface area and porosity analyzer (Micromeritics, ASAP 2020). The gas used for the adsorptive analysis was $\mathrm{N}_{2}$ and the analysis temperature was $-195{ }^{\circ} \mathrm{C}$. Prior to the measurement process, each sample was degassed at $300{ }^{\circ} \mathrm{C}$ overnight. The BET (Brunauer-EmmettTeller) method was utilized to calculate the surface area $\left(S_{\mathrm{BET}}\right)$ in the relative pressure range of 0.05 to 0.25 . The total pore volume $\left(V_{\mathrm{T}}\right)$ was obtained at $P / P_{0}=0.995$. The $t$-plot method was utilized to calculate the micropore volume $\left(V_{\text {micro }}\right)$, while subtracting the total pore volume from the result obtained from the $t$-plot will give the external volume $\left(V_{\text {ext }}\right)$. The pore size distribution (PSD) was obtained using SAIEUS software with 2D-NLDFT. ${ }^{23}$

The adsorption-desorption of $\mathrm{CO}_{2}$ was examined using a gravimetric method. $1 \mathrm{~g}$ of the ZTC sample was dried at $105^{\circ} \mathrm{C}$ for $2 \mathrm{~h}$. The ZTC was then cooled at room temperature and stored inside a desiccator. The adsorption-desorption process was conducted at temperatures of $30{ }^{\circ} \mathrm{C}, 40{ }^{\circ} \mathrm{C}$, and $50{ }^{\circ} \mathrm{C}$.

\section{$\mathrm{CO}_{2}$ adsorption-desorption measurement}

Gravimetric measurement. The gravimetric measurement was conducted on an in-house gravimetric apparatus. $1.3 \mathrm{~g}$ of the sample was degassed at $350{ }^{\circ} \mathrm{C}$ for $3 \mathrm{~h}$ prior to the adsorption-desorption measurement. The adsorption-desorption process was conducted at temperatures of $30{ }^{\circ} \mathrm{C}, 40{ }^{\circ} \mathrm{C}$, and $50{ }^{\circ} \mathrm{C}$ under a pressure of 1 bar using three different fresh samples. The $\mathrm{CO}_{2}$ flow rate during the adsorption process was controlled at $20 \mathrm{~mL} \mathrm{~min}^{-1}$. The desorption measurements were conducted simultaneously after the adsorption reached equilibrium and were assisted by vacuum. The alteration of mass was recorded by the Ohaus Pioneer analytical balance. The adsorption-desorption system used in this study is illustrated in Fig. 2.

Eqn (1) was used to determine the weight of adsorbed $\mathrm{CO}_{2}$ :

$$
\mathrm{CO}_{2} \mathrm{wt}^{\mathrm{O}} \%=\frac{M_{\mathrm{eq}}-M_{0}}{M_{0}+\left(M_{\mathrm{eq}}-M_{0}\right)} \times 100 \%
$$


a)

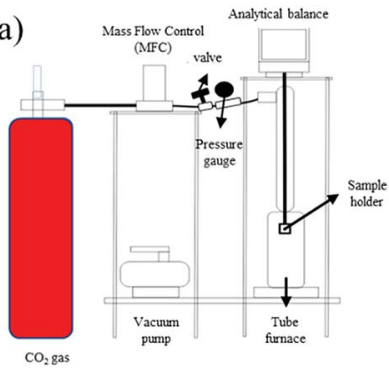

Fig. 2 Schematic diagram of the (a) adsorption system and (b) desorption system.

where $M_{\mathrm{eq}}$ is the mass after adsorption reached equilibrium and $M_{0}$ is the initial mass of the adsorbent after the degassing process. Eqn (2) was utilized for the desorption process:

$$
\% \mathrm{CO}_{2} \text { desorbed }=\frac{M_{\mathrm{T}}}{M_{\mathrm{eq}}} \times 100 \%
$$

where $M_{\mathrm{T}}$ is the remaining mass of $M_{\mathrm{eq}}$ at time $T$. Each measurement was repeated five times to ensure the accuracy of the data.

\section{Adsorption kinetics}

Kinetic models are used to determine gas transport mechanisms and adsorption types of $\mathrm{CO}_{2}$ into ZTC. In this study, pseudo-first order, pseudo-second order, and intra-particle diffusion models were used. ${ }^{24,25}$

Pseudo-first order. Generally, the model used to describe the adsorption process is given by eqn (3):

$$
\ln \left(q_{\mathrm{e}}-q_{t}\right)=\ln q_{\mathrm{e}}-k_{1} t
$$

where $q_{t}\left(\mathrm{mmol} \mathrm{g}^{-1}\right)$ is the amount of adsorbate adsorbed at the time of $t$ (minute), $q_{\mathrm{e}}\left(\mathrm{mmol} \mathrm{g}^{-1}\right)$ is the adsorption capacity at equilibrium and $k_{1}\left(\mathrm{~min}^{-1}\right)$ is the rate constant of the pseudofirst order.

Pseudo-second order. The pseudo-second order can be determined using eqn (4):

$$
\frac{\mathrm{d} q_{t}}{\mathrm{~d} t}=k_{\mathrm{s}}\left(q_{\mathrm{e}}-q_{t}\right)^{2}
$$

After integrating and applying boundary conditions, the equation can be integrated further with the initial condition of $q_{t}$ $=0$ at $t=0$ and $q_{t}=q_{t}$ at $t=t$. A linear equation can be obtained

$$
\frac{t}{q_{t}}=\frac{1}{k_{\mathrm{s}} q_{\mathrm{e}}^{2}}+\frac{1}{q_{\mathrm{e}}} t
$$

and the initial sorption rate, $h\left(\mathrm{mg} \mathrm{g}^{-1} \min ^{-1}\right)$ as $t \rightarrow 0$ can be defined as

$$
h=k_{\mathrm{s}} q_{\mathrm{e}}^{2}
$$

Intra-particle diffusion. Intra-particle diffusion was used to determine the adsorption process in porous materials and is expressed in eqn (7):

$$
q_{t}=k_{\mathrm{id}} t^{\frac{1}{2}}+C
$$

where, $t$ is time (min). The diffusion constant $k_{\text {id }}\left(\mathrm{mmol} \mathrm{g}^{-1}\right.$ $\min ^{-0.5}$ ) can be determined experimentally from the slope of the plot of $q_{t}$ versus $t^{1 / 2}$, and $C$ is an intercept that expresses the thickness of the boundary layer. ${ }^{1-3}$

\section{Thermodynamics adsorption}

A thermodynamic study was conducted to confirm the kinetic study and to determine the adsorption characteristics of $\mathrm{CO}_{2}$ into ZTC. The thermodynamic parameters were determined using the van't Hoff equation, given in eqn (8).

$$
\ln \frac{p}{p_{0}}=\frac{\Delta H}{R T}-\frac{\Delta S}{R}
$$

where $\Delta H$ is enthalpy adsorption $\left(\mathrm{kJ} \mathrm{mol}^{-1}\right), T$ is temperature $(\mathrm{K}), p$ is pressure at the equilibrium state (bar), $q$ is the adsorption capacity at the equilibrium state, and $R$ is a gas constant $\left(8.314 \mathrm{~J} \mathrm{~mol}^{-1} \mathrm{~K}^{-1}\right)$.

\section{Result and discussion}

\section{Synthesis of zeolite-Y-templated carbon}

Fig. 3 shows the diffractogram pattern of the prepared carbon sample and the corresponding zeolite template used in this study. The (111) planes of the zeolite-Y crystal were observed in a high peak around $\sim 6^{\circ}$, indicating a highly arranged zeolite crystal formation. The peak remains intact even after impregnation in acid and pyrolysis, since zeolite-Ys have high resistance toward sulfuric acid up to $5 \mathrm{M},{ }^{22}$ indicating that the structure of the zeolite-Y did not change during the process. However, the intensity was reduced after the carbon filling processes, but the intensity of the other peaks did not change significantly. On the other hand, the peak at $\sim 6^{\circ}$ was not found in the diffractogram pattern of the ZTC. This indicates low replication of the carbon to the template structure. This result was also observed previously. ${ }^{19} \mathrm{~A}$ broad, weak peak in the $2 \theta$

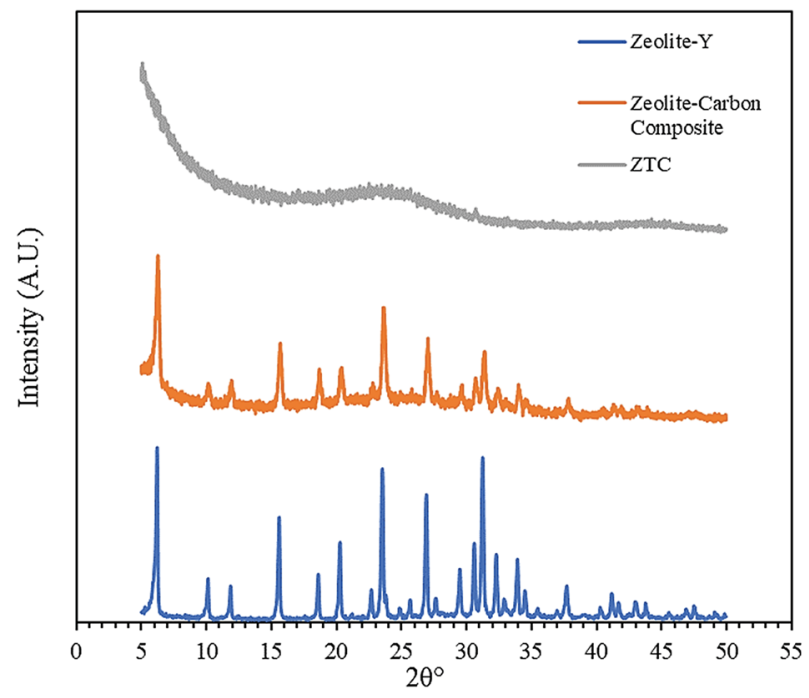

Fig. 3 Diffractogram patterns of the as-prepared samples. 
range of $20-25^{\circ}$ was observed. This is a reflection of (002) mesophase graphite-like material and often appears in such material. ${ }^{17,18}$ Interestingly, wide angle peaks at $\sim 43^{\circ}$, which correspond to the (101) of graphitic carbon, were not observed in this sample. This indicates that the ZTC material still replicated the structure of a zeolite body and even possesses mesoporous characteristics.

Fig. 4 shows the SEM and TEM images of the prepared samples. As shown in Fig. 4(1a), the morphology of zeolite-Y exhibits a typical crystal-like structure with an octahedral configuration, and the particle size was about 400-600 $\mathrm{nm}$. The same morphology was also observed for the composite and ZTC sample. However, a thin layer of graphitic carbon was observed on the surface of both the composite and ZTC, as marked in yellow circles on their respective TEM images. We suggest this layer is the reason for the broad, weak peak in the $2 \theta$ range of $20-25^{\circ}$ that appeared in the diffractogram data of ZTC. Moreover, to observe the element distribution after the impregnation and pyrolysis process, a TEM + EDX observation was conducted, as shown in Fig. 5. As can be seen in the EDX mapping, the carbon distribution was mainly inside the zeolite body, with a small amount of it on the outer side of the zeolite. This result confirms the XRD and SEM results discussed previously.

Fig. 6 shows the $\mathrm{N}_{2}$ isotherms of all the as-prepared samples. All the samples show typical type 1 adsorption, which indicates microporous materials. However, in both the composite and ZTC, type H4 hysteresis was observed. This hysteresis suggests the presence of mesopores in both material and narrow slit pores. ${ }^{26}$ The specific surface area $\left(S_{\mathrm{BET}}\right)$ of the ZTC was the highest of them all, reaching up to $1254.38 \mathrm{~m}^{2} \mathrm{~g}^{-1}$, almost double the $S_{\text {BET }}$ of zeolite-Y, which was $678.48 \mathrm{~m}^{2} \mathrm{~g}^{-1}$. In
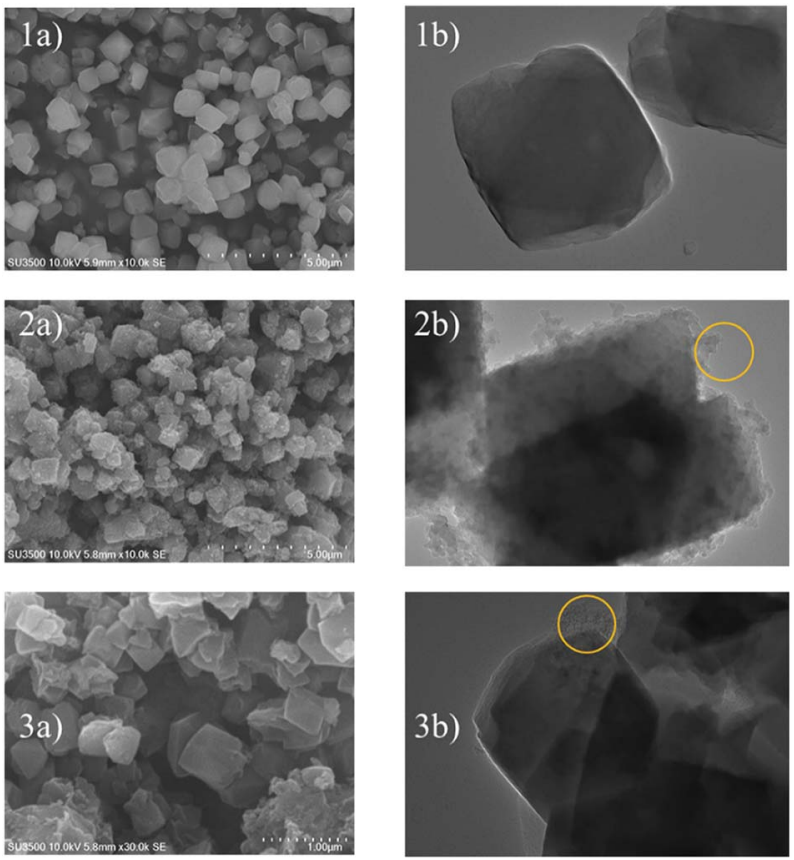

Fig. 4 SEM (a) and TEM (b) images of zeolite-Y (1), composite carbon (2), and ZTC (3). The yellow circles correspond to the external graphitic carbon.

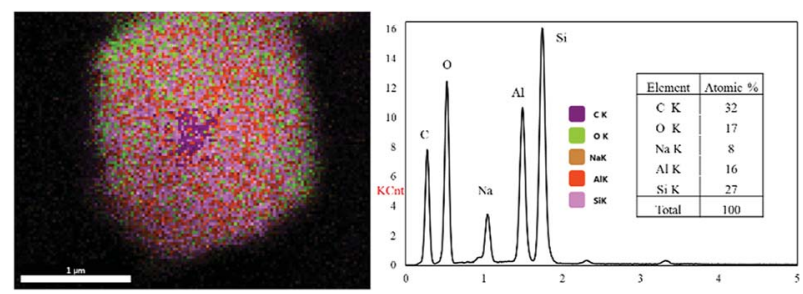

Fig. 5 The EDX mapping image of the composite (left) and the atomic distribution in it (right).

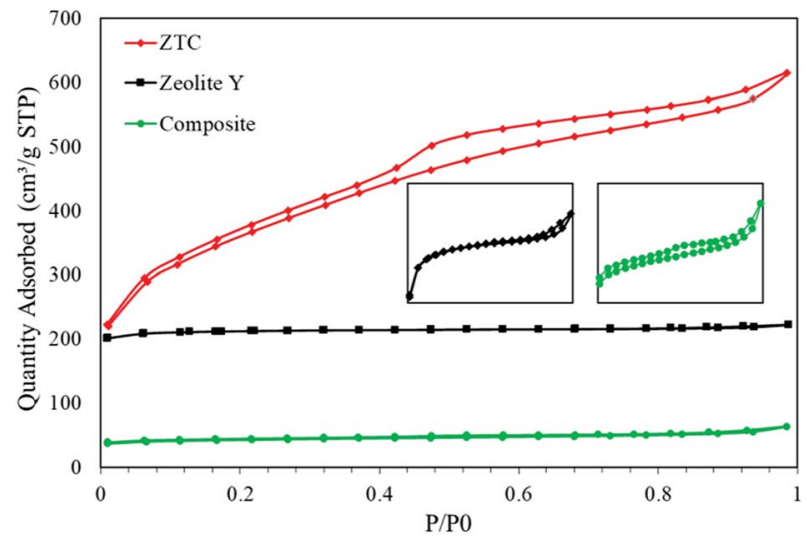

Fig. 6 The $\mathrm{N}_{2}$ isotherm graph of zeolite-Y, composite and ZTC.

contrast, the $S_{\mathrm{BET}}$ of the composite was the smallest of them all, which was only $133.29 \mathrm{~m}^{2} \mathrm{~g}^{-1}$. The reduction of the $S_{\mathrm{BET}}$ in the composite was because the pore of the zeolite was filled by carbon from the sucrose precursor. This indicates that the impregnation process was successful. The $S_{\mathrm{BET}}$ trend was followed by the pore volume result. The pore volumes of the zeolite-Y, composite, and ZTC were $0.344 \mathrm{~cm}^{3} \mathrm{~g}^{-1}, 0.098 \mathrm{~cm}^{3}$ $\mathrm{g}^{-1}$, and $0.945 \mathrm{~cm}^{3} \mathrm{~g}^{-1}$, respectively. These results proved that carbon preparation through a simple method of impregnation using a zeolite as a hard template will produce carbon that has a high pore volume and surface area.

The pore size distribution (PSD) was determined using SAIEUS software with 2D-NLDFT. The result is illustrated in Fig. 6. As can be seen in Fig. 7, the PSD of both the zeolite-Y and

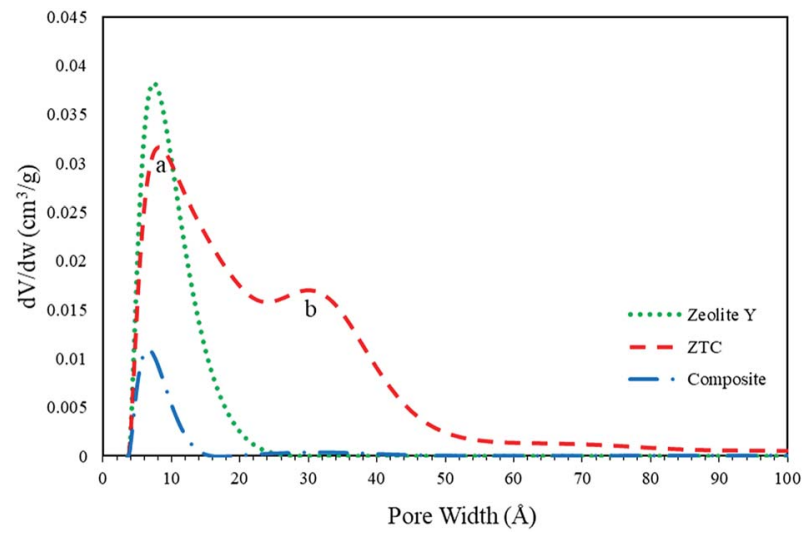

Fig. 7 The PSD obtained from 2D-NLDFT calculations. 
composite show a sharp peak, indicating narrow pore size distributions. The only big difference between these two graphs was the peak intensity (volume). The peak intensity of the zeolite is higher. The presence of carbon inside the zeolite pore not only reduced the pore volume significantly, but also reduced the average pore size of the zeolite-Y from $8.61 \pm 0.07 \AA$ to 7.29 $\pm 0.04 \AA$. The small pore of the composite has potential in applications that do not rely much on surface area and pore volume, such as for separation processes. On the other hand, the PSD of ZTC showed abroad peak, which was divided into two regions, $a$ and $b$. Region a was microporous region with an average pore diameter of $9.23 \pm 0.10 \AA$, and the size of this region was almost twice that of region $b$. Region $b$ corresponds to the mesoporous site with an average pore diameter of $24.55 \pm$ $0.84 \AA$ A. Moreover, the overall average pore size of ZTC was in the mesopore region which originated from imperfect sucrose impregnation. It can be concluded that the mesoporous region lies in the outer part of ZTC. This result was in agreement with the XRD, SEM, and TEM results discussed above. The presence of high micropores in ZTC would improve the $\mathrm{CO}_{2}$ adsorption, while the presence of mesopores would speed up the adsorption process. $^{27}$ The physical characteristics of all samples are summarized in Table 1.

\section{$\mathrm{CO}_{2}$ adsorption}

The $\mathrm{CO}_{2}$ adsorption was conducted at various temperatures $\left(30{ }^{\circ} \mathrm{C}, 40{ }^{\circ} \mathrm{C}\right.$, and $50{ }^{\circ} \mathrm{C}$ ) and 1 bar. The adsorption

Table 1 The physical properties of all samples

\begin{tabular}{llll}
\hline Parameters & ZTC & Composite & Zeolite-Y \\
\hline$S_{\text {BET }}\left(\mathrm{m}^{2} \mathrm{~g}^{-1}\right)$ & 1254.38 & 133.29 & 678.48 \\
$t$-Plot micropore area & 1051.72 & 96 & 620 \\
Pore volume $\left(\mathrm{cm}^{3} \mathrm{~g}^{-1}\right)$ & 0.95 & 0.10 & 0.34 \\
Average pore size $(\mathrm{nm})$ & $1.55 \pm 0.64$ & $0.73 \pm 0.04$ & $0.86 \pm 0.07$
\end{tabular}

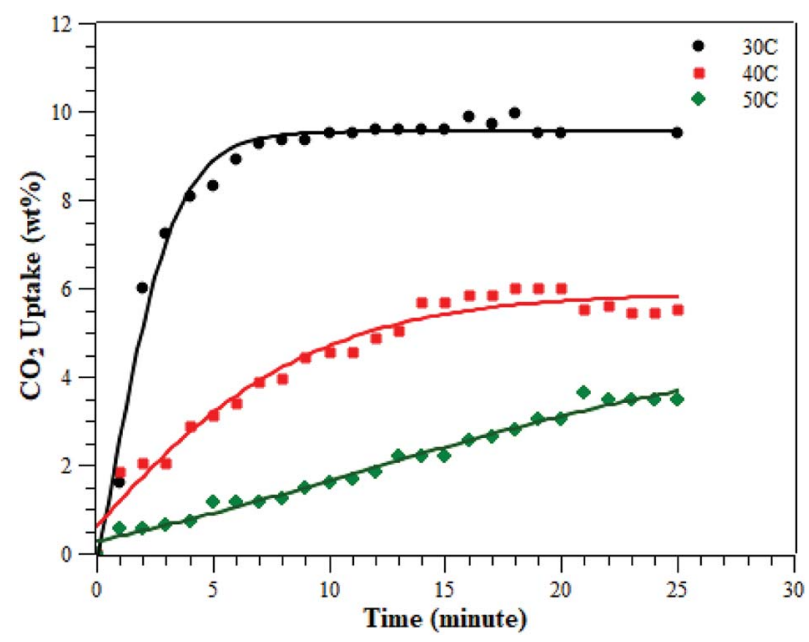

Fig. 8 The adsorption of $\mathrm{CO}_{2}$ on $\mathrm{ZTC}$ at various temperatures under a pressure of 1 bar. measurement results can be seen in Fig. 8 and Table 2. The results showed that the adsorption conducted at $30{ }^{\circ} \mathrm{C}$ had the greatest adsorption $\mathrm{CO}_{2}$ capacity of $9.51 \pm 0.48 \mathrm{wt} \%$, followed by the adsorption at $40{ }^{\circ} \mathrm{C}$ and then at $50{ }^{\circ} \mathrm{C}$ of $5.60 \pm 0.28$ and $3.47 \pm 0.17 \mathrm{wt} \%$, respectively. This indicates that $\mathrm{CO}_{2}$ adsorption occurs preferentially at a lower temperature. ${ }^{3,28-30}$ The $\mathrm{CO}_{2}$ adsorption capacity at $30{ }^{\circ} \mathrm{C}$ was higher than at the other two temperatures, due to physisorption and the fact that $\mathrm{CO}_{2}$ adsorption on porous materials requires a matching of pore sizes. Since the PSD of the ZTC mainly consisted of micropores, it had a high $\mathrm{CO}_{2}$ uptake due to pore matching with the $\mathrm{CO}_{2}$ molecular size. It was already confirmed that $\mathrm{CO}_{2}$ uptake is only determined by pores smaller than a certain diameter, not by the total pore volume. ${ }^{3,27}$ Moreover, the temperature-dependent size also plays an important role for $\mathrm{CO}_{2}$ sorption. Zhang et al. reported that the $\mathrm{CO}_{2}$ adsorption capacity at $75^{\circ} \mathrm{C}, 25^{\circ} \mathrm{C}$ and $0{ }^{\circ} \mathrm{C}$ and a pressure of 1 bar was determined by micropores of $0.54 \mathrm{~nm}, 0.7 \mathrm{~nm}$, and $0.8 \mathrm{~nm}$ in size, respectively. ${ }^{31}$ Since the ZTC studied here possesses mesopores that make up 50\% of the amount of micropores, the adsorption at elevated temperatures decreased significantly since there was no suitable space to which the $\mathrm{CO}_{2}$ molecules could attach. In summary, the adsorption at $30^{\circ} \mathrm{C}$ was mainly in the micropore sites of zone (a) in the PSD curve, while the adsorption at $50{ }^{\circ} \mathrm{C}$ was mainly in the mesopore sites of zone (b). Additionally, since the pore structure of the ZTC studied here has a micro-mesoporous pore structure, it has its own benefit to enhance the transfer of $\mathrm{CO}_{2}$ molecules into and out of the inner microporous network. ${ }^{27}$

The desorption process was conducted by a gravimetric method and by using various desorption temperatures. The desorption process took place immediately after the adsorption process was completed. The decreases in mass inside the adsorbent were plotted against time. The desorption results at various temperatures can be seen in Fig. 9 and Table 3 below.

As can be seen in Fig. 9, the desorption capacity of $\mathrm{CO}_{2}$ increases as the temperature increases. As shown in Table 2, the amount of $\mathrm{CO}_{2}$ desorbed at $30{ }^{\circ} \mathrm{C}, 40{ }^{\circ} \mathrm{C}$, and $50{ }^{\circ} \mathrm{C}$ was $59.83 \%$, $69.70 \%$, and $77.5 \%$, respectively. The release of $\mathrm{CO}_{2}$ was slower by the time being, except at a temperature of $50{ }^{\circ} \mathrm{C}$. The time needed to achieve desorption equilibrium is shorter at elevated temperatures. As discussed in a previous section, the desorption process can be described as the reverse process of the adsorption process. This also means that all the parameters that affect the adsorption capacity also have an effect on the desorption process. Since the adsorption at $30{ }^{\circ} \mathrm{C}$ mostly took place in the micropore sites, the desorption from this this region was the slowest because the gas movement was limited to small channels. This resulted in slower, multilayer breaking inside the pores. In contrast, the desorption at $50{ }^{\circ} \mathrm{C}$ took place faster because a small amount of $\mathrm{CO}_{2}$ adsorbed at the matching pore size and mostly occupied the mesopore region of the ZTC.

\section{Regenerative ability of the sorbent}

In order to study the regenerative ability of the ZTC sorbent, five simultaneous runs of the adsorption-desorption process at $30{ }^{\circ} \mathrm{C}, 40{ }^{\circ} \mathrm{C}$, and $50{ }^{\circ} \mathrm{C}$ were conducted. The results are shown 
Table $2 \mathrm{CO}_{2}$ adsorption on ZTC at various temperatures and a pressure of 1 bar, compared with other carbon materials

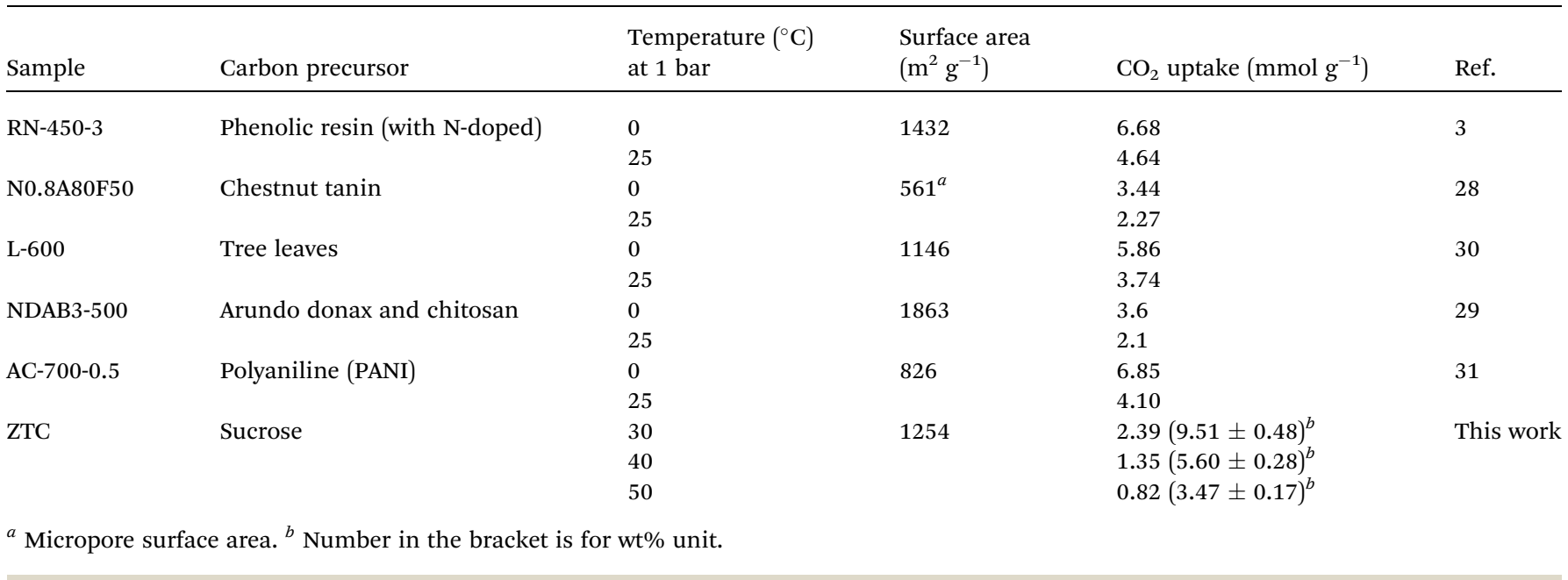

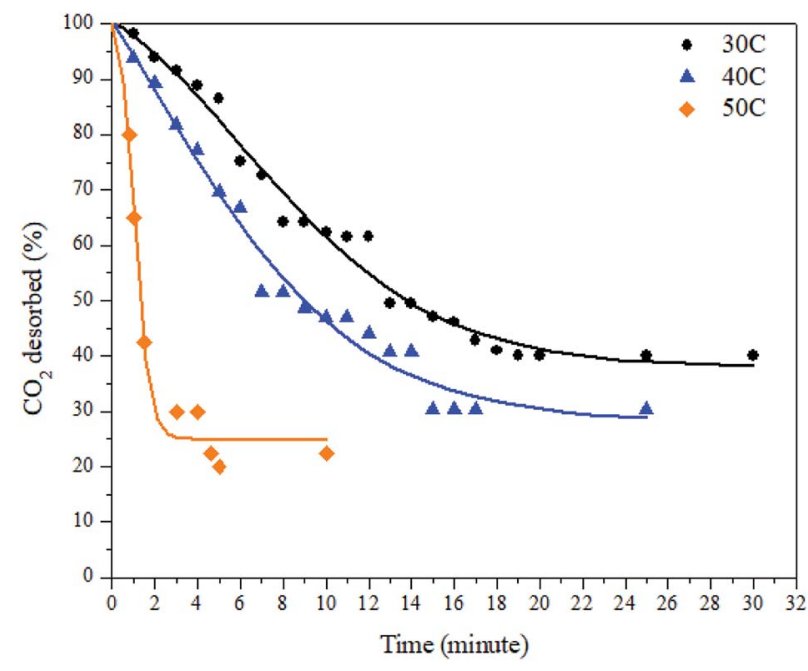

Fig. 9 Desorption of $\mathrm{CO}_{2}$ on the ZTC at various temperatures and a pressure of 1 bar.

in Fig. 10. Prior to measurement, the initial mass of the absorbent was neglected and set to zero on an analytical balance. This allowed for easier data records of the changes in mass captured by the instrument, considered as the mass of $\mathrm{CO}_{2}$. All the measurements were taken at minute 30. Even though the sorbent was unable to release all of the $\mathrm{CO}_{2}$, as discussed in a previous section, this did not greatly affect the $\mathrm{CO}_{2}$ uptake capacity after five runs of the adsorption-

Table 3 Desorption of $\mathrm{CO}_{2}$ on the $\mathrm{ZTC}$ at various temperatures and a pressure of 1 bar $^{a}$

\begin{tabular}{lcc}
\hline Temperature $\left({ }^{\circ} \mathrm{C}\right)$ & $t_{50}$ (minute) & $Q_{\text {des }}(\%)$ \\
\hline 30 & 15 & 59.83 \\
40 & 7 & 69.70 \\
50 & 3 & 77.50
\end{tabular}

${ }^{a} t_{50}$, time needed to release $50 \%$ of the $\mathrm{CO}_{2}$. Q $Q_{\text {des }}$, maximum amount of $\mathrm{CO}_{2}$ desorbed. desorption process. The notable changes between the first and fifth runs in the reduction adsorption capacity for the process conducted at $30{ }^{\circ} \mathrm{C}, 40{ }^{\circ} \mathrm{C}$, and $50{ }^{\circ} \mathrm{C}$ were $6.23 \%, 12.97 \%$, and $26.80 \%$, respectively, suggesting the high potential of repeated $\mathrm{CO}_{2}$ capture usage at low temperature. A similar trend was also observed in the desorption process, which is shown in Fig. 11. The notable reduction in the amount of $\mathrm{CO}_{2}$ desorbed was $8.57 \%, 9.52 \%$, and $9.68 \%$ for the process conducted at $30{ }^{\circ} \mathrm{C}$, $40{ }^{\circ} \mathrm{C}$, and $50{ }^{\circ} \mathrm{C}$, respectively. The results show the great regenerative ability of the studied sorbent.

\section{Adsorption kinetics}

The results of the kinetics study can be seen in Fig. 12. The adsorption kinetics of $\mathrm{CO}_{2}$ gas are really important to explain the adsorption mechanism. The kinetics model used is based on the observed samples. A lot of research has reported on the adsorption kinetics of gases at solid surfaces. Most of them used pseudo-first order, pseudo-second order and intra-particle diffusion models., ${ }^{3,28,29}$ Therefore, in this paper, those models were used to explain the $\mathrm{CO}_{2}$ adsorption mechanism in the

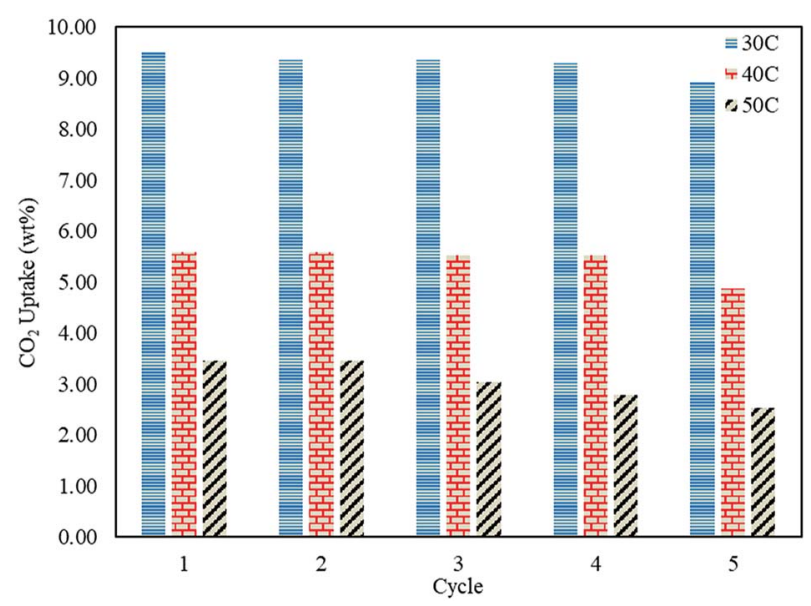

Fig. 10 The $\mathrm{CO}_{2}$ uptake changes after five adsorption-desorption cycles. 


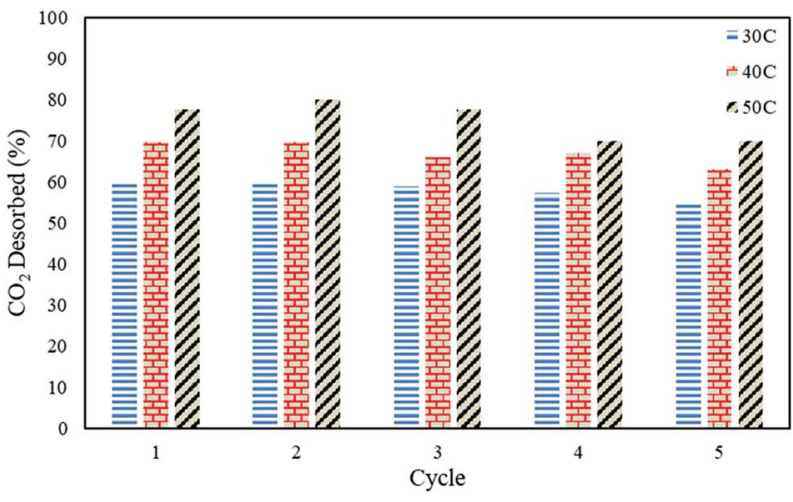

Fig. $11 \mathrm{CO}_{2}$ desorption capacity on the ZTC after five consecutive runs.

carbon template zeolite based on its physical and chemical properties, to match the experimental data, and also to study the mass transport process.

The assumption used in the pseudo-first order model is that the concentration of one reactant is much higher than the concentration of the other reactants. ${ }^{25}$ The pseudo-first order model's equation can be seen in eqn (1). The plot of this model is shown in Fig. 12a.

The assumption used in the pseudo-second order model is the availability of active sites on the adsorbent surface is always proportional to the adsorption capacity. ${ }^{32}$ The pseudo-second order's equation can be seen in eqn (3). The plot of this model is shown in Fig. 12b.

The intra-particle diffusion equation can be seen in eqn (4). By plotting $q_{t}$ (the capacity of adsorbed $\mathrm{CO}_{2}$ at time, $t$, in mmol $\mathrm{g}^{-1}$ ) against $t^{1 / 2}$, the intra-particle diffusion graph (Fig. 12c) was obtained. Fig. $12 \mathrm{c}$ shows two adsorption steps at $50^{\circ} \mathrm{C}$, the first one is external surface adsorption, or macropore diffusion, and the last is internal surface adsorption, or micropore diffusion. External diffusion occurs faster than internal diffusion. ${ }^{33}$

The important kinetic parameters are summarized in Table 3. Table 3 shows that the $\mathrm{CO}_{2}$ adsorption taken at temperatures of $30^{\circ} \mathrm{C}$ and $40^{\circ} \mathrm{C}$ follows the pseudo-second order as it has the biggest $R^{2}$ value. This means that at these temperatures $\left(30^{\circ} \mathrm{C}\right.$ and $40{ }^{\circ} \mathrm{C}$ ) the adsorption capacity is a proportional to the amount of active sites/micropores available on the adsorbent surface. ${ }^{29}$ It showed that at these temperatures there was a lot of available active sites for $\mathrm{CO}_{2}$ gases. Moreover, this result also suggests that $\mathrm{CO}_{2}$ adsorption at the corresponding temperature was mainly controlled by physical adsorption. On the other hand, the adsorption conducted at $50{ }^{\circ} \mathrm{C}$ follows the intraparticle diffusion model as it gives the biggest $R^{2}$ value. At $30{ }^{\circ} \mathrm{C}$ it can be assumed that the $\mathrm{CO}_{2}$ gas entered the adsorbent pores via two steps, the first is fast external diffusion through mesopores, followed by slow internal diffusion into the micropores of the ZTC. The experiment conducted at $50{ }^{\circ} \mathrm{C}$ did not show the same adsorption behaviour. In that case, the $\mathrm{CO}_{2}$ penetrated the ZTC pores with ease. The adsorption at $40{ }^{\circ} \mathrm{C}$ showed an in between behaviour, indicating that this was the point where the surface properties of the ZTC began to change due to the increase in temperature. Overall, the intra-particle diffusion model suggests that the $\mathrm{CO}_{2}$ mass transport into the ZTC was highly affected by the adsorption temperature. However, further investigation, such as molecular modelling is needed to study the phenomena.

In Table $4 k_{\mathrm{f}}$ is the pseudo-first order rate constant $\left(\mathrm{min}^{-1}\right)$, $q_{\mathrm{e}}$ is the adsorption capacity at equilibrium $\left(\mathrm{mmol} \mathrm{g}^{-1}\right), h$ is the pseudo-second initial rate constant $\left(\mathrm{mmol} \mathrm{g}^{-1}\right), k_{\mathrm{d}}$ is the diffusion rate constant $\left(\mathrm{mmol} \mathrm{g}^{-1} \mathrm{~min}^{-0.5}\right)$, and $\mathrm{C}$ is the intercept that expresses the layer boundary thickness.

\section{Thermodynamic adsorption}

Thermodynamic parameters such as enthalpy $(\Delta H)$, entropy $(\Delta S)$ and the change in the Gibbs free energy $(\Delta G)$ were obtained from eqn (6). Plotting $\ln \left(p / p_{0}\right)$ versus $1 / T$ gives a slope equal to the enthalpy $(\Delta H)$ and an intercept equal to the entropy $(\Delta S)$, as can be seen in Fig. 13. The results are summarized in Table 5.

Adsorption heat (enthalpy) shows the interaction power between the adsorbate and adsorbent. ${ }^{24}$ From the experimental data, the enthalpy $(\Delta H)$ was $-4792 \mathrm{~kJ} \mathrm{~mol}^{-1}$. The negative value of the enthalpy shows that the adsorption process was exothermic. The value of enthalpy is $<80 \mathrm{~kJ} \mathrm{~mol}^{-1}$, which means the adsorption process of $\mathrm{CO}_{2}$ on the ZTC was controlled via physisorption. ${ }^{4}$ Chemical bonding between the adsorbent and adsorbate does not exist, but the interactions are due to the differences of dipole-dipole on the adsorbent surface to the atoms in the adsorbate. Generally, the enthalpy was influenced by the amount of gas that covered the adsorbent surface. When the amount of adsorbate that covered the adsorbent surface was low, there was a strong interaction between the adsorbent and adsorbate. a)

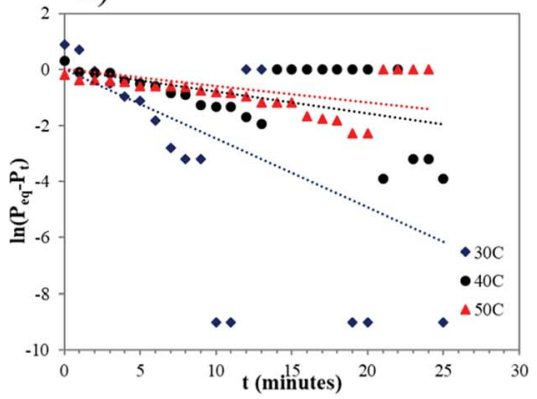

b)

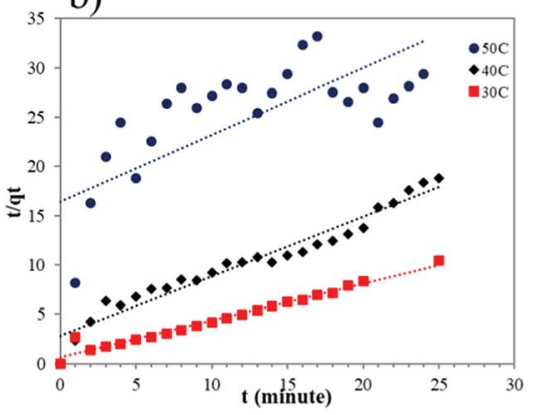

c)

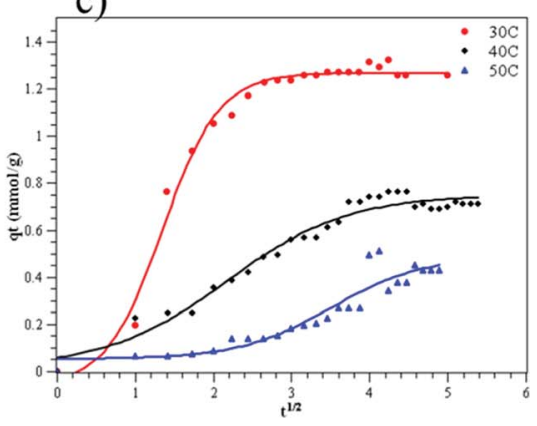

Fig. 12 Graph of (a) pseudo-first order, (b) pseudo-second order, and (c) intra-particle diffusion models. 
Table 4 Parameters of each kinetic model

\begin{tabular}{|c|c|c|c|}
\hline \multirow{2}{*}{$\begin{array}{l}\text { Model } \\
\begin{array}{l}\text { Pseudo-first } \\
\text { order }\end{array}\end{array}$} & \multicolumn{3}{|c|}{ Parameters } \\
\hline & $k_{\mathrm{f}}$ & $q_{\mathrm{e}}$ & $R^{2}$ \\
\hline $30{ }^{\circ} \mathrm{C}$ & -0.04 & 1 & 0.28 \\
\hline $40{ }^{\circ} \mathrm{C}$ & -0.07 & 1 & 0.15 \\
\hline $50{ }^{\circ} \mathrm{C}$ & -0.08 & 1 & 0.76 \\
\hline Model & \multicolumn{3}{|c|}{$\underline{\text { Parameters }}$} \\
\hline $\begin{array}{l}\text { Pseudo-second } \\
\text { order }\end{array}$ & $h$ & $q_{\mathrm{e}}$ & $R^{2}$ \\
\hline $30{ }^{\circ} \mathrm{C}$ & 1.66 & 2.66 & 0.97 \\
\hline $40^{\circ} \mathrm{C}$ & 0.36 & 1.65 & 0.95 \\
\hline $50{ }^{\circ} \mathrm{C}$ & 0.06 & 1.47 & 0.47 \\
\hline Model & Param & & \\
\hline
\end{tabular}

\begin{tabular}{lllll}
\hline Intra-particle & & & \\
\cline { 3 - 4 } diffusion & & & & \\
\hline & & & $R^{2}$ \\
\hline $30{ }^{\circ} \mathrm{C}$ & 0.24 & 0.38 & 0.71 \\
$40^{\circ} \mathrm{C}$ & 0.13 & 0.10 & 0.88 \\
$50^{\circ} \mathrm{C}$ & 0.12 & -0.17 & 0.92
\end{tabular}

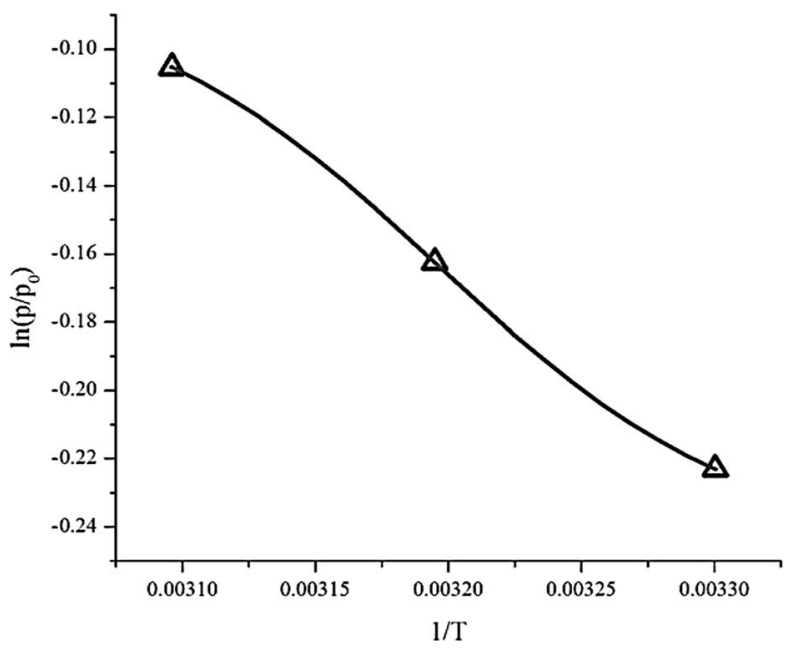

Fig. 13 Graph of thermodynamic adsorption.

The entropy change $(-\Delta S)$ obtained was $13.959 \mathrm{~J} \mathrm{~K}^{-1} \mathrm{~mol}^{-1}$. The negative value of entropy suggests a decrease in randomness at the gas-solid interface during the adsorption process. $^{24,34}$ This means that the mobility of the $\mathrm{CO}_{2}$ gas is limited inside the ZTC pore.

The Gibbs free energy change $(\Delta G)$ has a negative value, as can be seen at Table 5. This negative value indicates that the adsorption process was spontaneous without any external energy. The Gibbs free energy change values increase as the temperature of adsorption increases. This showed that at higher temperature the adsorption of $\mathrm{CO}_{2}$ is less spontaneous which agreed with the kinetics data.
Table 5 The thermodynamic parameters of $\mathrm{CO}_{2}$ adsorption on zeolite-Y-templated carbon $^{a}$

\begin{tabular}{llll}
\hline Temperature & $\begin{array}{l}\Delta H \\
\left(\mathrm{~kJ} \mathrm{~mol}^{-1}\right)\end{array}$ & $\begin{array}{l}\Delta S \\
\left(\mathrm{~J} \mathrm{~mol}^{-1}\right)\end{array}$ & $\begin{array}{l}\Delta G \\
\left(\mathrm{~kJ} \mathrm{~mol}^{-1}\right)\end{array}$ \\
\hline $30{ }^{\circ} \mathrm{C}$ & -4.79 & -13.96 & -0.56 \\
$40^{\circ} \mathrm{C}$ & & -0.42 \\
$50{ }^{\circ} \mathrm{C}$ & -0.28 \\
${ }^{a} \Delta S=$ the change in entropy. $\Delta H=$ the change in enthalpy. $\Delta G=$ the \\
change in Gibbs free energy.
\end{tabular}
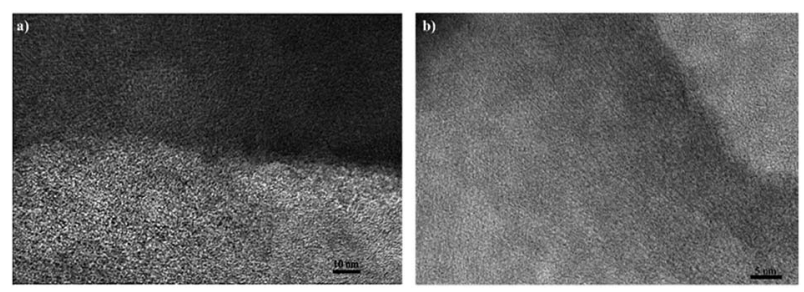

Fig. 14 The HRTEM image of (a) the outer and inner surface of ZTC and (b) the inner surface of ZTC.

The structure relation of ZTC toward $\mathrm{CO}_{2}$ adsorptiondesorption performance

To sum up our study, a comprehensive study of the ZTC structure was conducted using HRTEM. Fig. 14a shows the outer layer of the ZTC, the brighter region in the image, and the inner surface of ZTC, the darker region in the image. The outer layer came from the unsuccessful sucrose impregnation, as discussed above. This outer layer mostly consisted of random pore structure orientation, bigger than $1 \mathrm{~nm}$ in size. This region was responsible for accelerating the $\mathrm{CO}_{2}$ transfer into the inner micropores of the ZTC due to its big pore. When moving a little bit deeper into the ZTC, the pore orientation changed into a more ordered structure. This ordered, straight, worm-like, stacked graphene structure was responsible for the majority of where the $\mathrm{CO}_{2}$ molecules adsorbed at a lower temperature, with a micropore size below $1 \mathrm{~nm}$. Moreover, Fig. 14b shows a more detailed inner region of the ZTC. It can clearly be seen that the micropores were ordered and interconnected. This regular pore structure assisted in reaching the $\mathrm{CO}_{2}$ adsorptiondesorption equilibrium faster and was somewhat similar to the structure of the zeolite-Y reported by Iyoki et al. ${ }^{35}$

\section{Conclusions}

In this paper, ZTC has been synthesized as a $\mathrm{CO}_{2}$ capturer. The ZTC was synthesized via three steps: sucrose impregnation, carbonization and template removal. The results showed that the adsorption capacity was $9.51 \pm 0.48 \mathrm{wt} \%, 5.60 \pm 0.28 \mathrm{wt} \%$, $3.47 \pm 0.17 \mathrm{wt} \%$ or $2.39 \mathrm{mmol} \mathrm{g}^{-1}, 1.35 \mathrm{mmol} \mathrm{g}^{-1}, 0.82 \mathrm{mmol}$ $\mathrm{g}^{-1}$ at temperatures of $30{ }^{\circ} \mathrm{C}, 40{ }^{\circ} \mathrm{C}$, and $50{ }^{\circ} \mathrm{C}$, respectively. The amounts of $\mathrm{CO}_{2}$ desorbed at temperatures of $30{ }^{\circ} \mathrm{C}, 40{ }^{\circ} \mathrm{C}$, and $50{ }^{\circ} \mathrm{C}$ were up to $59.83 \%, 69.70 \%, 77.5 \%$, respectively. Multiple runs showed that the adsorption process of $\mathrm{CO}_{2}$ at temperatures 
of $30{ }^{\circ} \mathrm{C}$ and $40{ }^{\circ} \mathrm{C}$ follows the pseudo-second order model with the highest degrees of determination $\left(R^{2}\right)$ of 0.972 and 0.967, while at $50{ }^{\circ} \mathrm{C}$ follows intra-particle diffusion with a degree of determination $\left(R^{2}\right)$ of 0.923 . The thermodynamic analyses determined the change of enthalpy $(\Delta H)$ and the change of entropy $(\Delta S)$ of $-4.791 \mathrm{~kJ} \mathrm{~mol}^{-1}$ and $-13.959 \mathrm{~J} \mathrm{~K}^{-1} \mathrm{~mol}^{-1}$, respectively. The free energy changes at temperatures of $30{ }^{\circ} \mathrm{C}$, $40{ }^{\circ} \mathrm{C}$, and $50{ }^{\circ} \mathrm{C}$ were $-0.562 \mathrm{~kJ} \mathrm{~mol}^{-1}, 0.422 \mathrm{~kJ} \mathrm{~mol}^{-1}$, and $-0.283 \mathrm{~kJ} \mathrm{~mol}^{-1}$, respectively. The adsorption process was exothermic as the value of $(\Delta H)$ was negative. The negative sign in the entropy change $(\Delta S)$ indicates the decreasing randomness on the gas-solid surface during the adsorption process. The Gibbs free energy change $(\Delta G)$ at temperatures of $30{ }^{\circ} \mathrm{C}$, $40{ }^{\circ} \mathrm{C}$, and $50{ }^{\circ} \mathrm{C}$ were $-0.562 \mathrm{~kJ} \mathrm{~mol}^{-1},-0.422 \mathrm{~kJ} \mathrm{~mol}^{-1}$, and $-0.283 \mathrm{~kJ} \mathrm{~mol}^{-1}$, respectively. The negative values of $(\Delta G)$ indicate that the adsorption process was spontaneously. With the micro-meso pore structure, this material is a good candidate for fast $\mathrm{CO}_{2}$ adsorption-desorption applications.

\section{Conflicts of interest}

There are no conflicts to declare.

\section{Acknowledgements}

The authors would like to acknowledge the Ministry of Research, Technology, and Higher Education Indonesia for providing financial support under PMDSU (Master heading to Doctor Program for Excellence Graduates) scholarship for doctoral degree for Triyanda Gunawan and Rika Wijiyanti as well as PMDSU research fund, grant number: [135/SP2H/LT/ DPRM/IV/2017, 3rd April 2017].

\section{References}

1 J. Yang, L. Yue, B. Lin, L. Wang, Y. Zhao, Y. Lin, K. Chang, H. DaCosta and X. Hu, Energy Fuels, 2017, 31, 11060-11068.

2 J. Chen, J. Yang, G. Hu, X. Hu, Z. Li, S. Shen, M. Radosz and M. Fan, ACS Sustainable Chem. Eng., 2016, 4, 1439-1445.

3 L. Wang, L. Rao, B. Xia, L. Wang, L. Yue, Y. Liang, H. DaCosta and X. Hu, Carbon, 2018, 130, 31-40.

4 R. L. Tseng, F. C. Wu and R. S. Juang, Sep. Purif. Technol., 2015, 140, 53-60.

5 T. H. Oh, Renewable Sustainable Energy Rev., 2010, 14, 26972709.

6 H. H. Tseng, G. L. Zhuang, M. Der Lin, S. H. Chang and M. Y. Wey, J. Membr. Sci., 2015, 495, 294-304.

7 B. S. Caglayan and A. E. Aksoylu, J. Hazard. Mater., 2013, 252253, 19-28.

8 J. D. Figueroa, T. Fout, S. Plasynski, H. McIlvried and R. D. Srivastava, Int. J. Greenhouse Gas Control, 2008, 2, 9-20. 9 W. W. Lestari, M. Adreane, C. Purnawan, H. Fansuri, N. Widiastuti and S. B. Rahardjo, IOP Conf. Ser.: Mater. Sci. Eng., 2016, 107, 012030.
10 C. H. Yu, C. H. Huang and C. S. Tan, Aerosol Air Qual. Res., 2012, 12, 745-769.

11 K. H. Chung, Energy, 2010, 35, 2235-2241.

12 P. Kelut, P. K. Kulkarni and P. A. D. Kulkarni, Chem. Process Eng. Res., 2014, 18, 7-15.

13 H. Nishihara and T. Kyotani, Zeolite-Templated Carbon - Its Unique Characteristics and Applications, Elsevier Ltd, 2012.

14 X. H. Song, R. Xu and K. Wang, J. Anal. Appl. Pyrolysis, 2013, 100, 153-157.

15 C. Guan, X. Zhang, K. Wang and C. Yang, Sep. Purif. Technol., 2009, 66, 565-569.

16 J. Shi, W. Li and D. Li, Colloids Surf., A, 2015, 485, 11-17.

17 J. Zhou, W. Li, Z. Zhang, W. Xing and S. Zhuo, RSC Adv., 2012, 2, 161-167.

18 H. K. Youn, J. Kim, G. Chandrasekar, H. Jin and W. S. Ahn, Mater. Lett., 2011, 65, 1772-1774.

19 C. Guan, K. Wang, C. Yang and X. S. Zhao, Microporous Mesoporous Mater., 2009, 118, 503-507.

20 C. Guan, F. Su, X. S. Zhao and K. Wang, Sep. Purif. Technol., 2008, 64, 124-126.

21 N. Brand, in Verified Syntheses of Zeolitic Materials, Elsevier, 2001, pp. 156-158.

22 X. Wang, K. Wang, C. A. Plackowski and A. V. Nguyen, Appl. Surf. Sci., 2016, 367, 281-290.

23 E. Redondo, W. Y. Tsai, B. Daffos, P. L. Taberna, P. Simon, E. Goikolea and R. Mysyk, Electrochem. Commun., 2017, 79, 5-8.

24 M. Delavar, A. A. Ghoreyshi, M. Jahanshahi, S. Khalili and N. Nabian, RSC Adv., 2012, 2, 4490-4497.

25 N. Widiastuti, H. Wu, H. M. Ang and D. Zhang, Desalination, 2011, 277, 15-23.

26 Z. A. Alothman, Materials, 2012, 5, 2874-2902.

27 X. Zhang, W. Li and A. Lu, New Carbon Mater., 2015, 30, 481501.

28 K. M. Nelson, S. M. Mahurin, R. T. Mayes, B. Williamson, C. M. Teague, A. J. Binder, L. Baggetto, G. M. Veith and S. Dai, Microporous Mesoporous Mater., 2016, 222, 94-103.

29 G. Singh, I. Y. Kim, K. S. Lakhi, S. Joseph, P. Srivastava, R. Naidu and A. Vinu, J. Mater. Chem. A, 2017, 5, 2119621204.

30 J. Xu, J. Shi, H. Cui, N. Yan and Y. Liu, Chem. Phys. Lett., 2018, 711, 107-112.

31 Z. Zhang, J. Zhou, W. Xing, Q. Xue, Z. Yan, S. Zhuo and S. Z. Qiao, Phys. Chem. Chem. Phys., 2013, 15, 2523.

32 Y. S. Ho and G. McKay, Process Biochem., 1999, 34, 451-465. 33 B. Zamora, A. A. Al-Hajjaj, A. A. Shah, D. V. Bavykin and E. Reguera, Int. J. Hydrogen Energy, 2013, 38, 6406-6416.

34 K. Soodabeh, G. Asghar and J. Mohsen, Chem. Ind. Chem. Eng. Q., 2012, 19, 50.

35 K. Iyoki, Y. Yamaguchi, A. Endo, Y. Yonezawa, T. Umeda, H. Yamada, Y. Yanaba, T. Yoshikawa, K. Ohara, K. Yoshida, Y. Sasaki, T. Okubo and T. Wakihara, Microporous Mesoporous Mater., 2018, 268, 77-83. 